\title{
COMPOSIÇÃO CENTESIMAL E TEOR DE $\beta$-GLUCANAS EM CEREAIS E DERIVADOS ${ }^{1}$
}

\author{
Alexandre H.FUJITA ${ }^{2}$, María O. R. FIGUEROA ${ }^{2, *}$
}

\begin{abstract}
RESUMO
Foi utilizado o método enzimático recomendado pela AOAC para determinação de $\beta$-glucanas em cereais e alimentos que os contém. O método, utiliza liquenase (EC 3.2.1.73) e $\beta$-glucosidase (EC 3.2.1.21) para hidrólise de $\beta$-glucanas, é rápido, fácil de executar e específico para $\beta$-glucanas com ligações $\beta(1 \rightarrow 3)$ e $\beta(1 \rightarrow 4)$. As sementes analisadas foram subministradas pelo Instituto Agronômico de Campinas (IAC) e os alimentos adquiridos nos supermercados. Aveia e cevada são os grãos com maior conteúdo de $\beta$-glucanas. Na aveia os teores determinados foram 6,48 e 5,94\%. Nos 10 cultivares de cevada os teores de $\beta$-glucanas oscilaram entre 2,04 e $9,68 \%$. Trigo e triticale apresentaram teores de $\beta$-glucanas menores que $1 \%$. Nos produtos comerciais o teor de $\beta$-glucanas estava relacionado ao tipo de cereal da fórmula. O produto comercial de maior conteúdo de $\beta$-glucanas é o farelo de aveia. As $\beta$-glucanas são ingredientes funcionais em potencial e a conveniência ou não de estimular sua incorporação em alimentos deve ser mais estudada. Quanto à composição centesimal dos grãos de cereais, o teor de proteínas foi o que apresentou a maior variação e isso se reflete na composição dos produtos comerciais. Palavras-chave: $\beta$-glicanas; cereais; aveia; cevada; composição; fibra solúvel; alimentos ou ingredientes funcionais.
\end{abstract}

\section{SUMMARY}

NUTRIENT PROFILE AND $\beta$-GLUCANS CONTENT IN CEREAL SEEDS AND FOODSTUFFS CONTAIN THEM. The method employed was the enzymatic one recommended by de AOAC for the determination of $\beta$-glucans in cereals and in foodstuffs containing cereals in their formulation. The method, using lichenase (EC 3.2.1.73) and $\beta$-glucosidase (EC 3.2.1.21) for the hydrolysis of $\beta$-glucans, is quick and easy to execute, but is specific for $\beta$-glucans with $\beta(1 \rightarrow 3)$ and $\beta(1 \rightarrow 4)$ bonds. The Agronomic Institute of Campinas (IAC) supplied the seeds analyzed, and the foodstuffs were acquired in supermarkets. Oat and barley are the grains with the highest content of $\beta$-glucans. In the oats, the determined values were 6.48 and $5.94 \%$. In the 10 cultivars of barley, the content of $\beta$-glucans varied between 2.04 and $9.68 \%$. Wheat and triticale had $\beta$-glucans contents lower than $1 \%$. Commercial products had contents of $\beta$-glucans according to the kind of cereal used in their formulas. The $\beta$-glucans are potential functional ingredients, and the convenience or not, of stimulating their incorporation in foodstuffs must be further considered. The protein contents were the most important variation of cereals and that was reflected in foodstuffs too.

Keywords: $\beta$-glucans; cereals; oat; barley; composition; soluble fiber; functional foods or ingredients.

\section{1 - INTRODUÇÃO}

As $\beta$-glucanas são polissacarídeos que fazem parte da fração solúvel da fibra alimentar, ocorrem nos cereais, principalmente cevada e aveia. Estão contidas no endosperma da semente e são uma cadeia linear de unidades $\beta$-D-glicopiranosil unidas por ligações $\beta(1 \rightarrow 4)$ e $\beta(1 \rightarrow 3)$. As ligações $\beta(1 \rightarrow 4)$ respondem aproximadamente por $70 \%$ das ligações glicosídicas, e ocorrem em seqüência de duas ou três unidades de glicose, interrompidas por uma ligação $\beta(1 \rightarrow 3)$ isolada. $[11,22]$.

Os primeiros estudos científicos de $\beta$-glucanas da cevada (Hordeum vulgare) foram estimulados pela influência destas substâncias na elaboração e na qualidade da cerveja. Porém, após a descoberta dos efeitos fisiológicos, as $\beta$-glucanas da aveia (Aveia sativa) de estrutura química similar, têm dividido a atenção.

As $\beta$-glucanas de cereais diminuem a taxa de colesterol plasmático, principalmente em indivíduos hipercolesterolêmicos $[4,17,18,20]$ e atenuam a resposta glicêmica e insulínica pós-prandial $[5,8,15]$, o que

1. Recebido para publicação em 26/04/2001. Aceito para publicação em 14/10/2002 (000617).

2.Depto de Alim e Nutr. Experim.,FCF, USP, Av. Prof. Lineu Prestes, 580, CEP 05508-900, São Paulo, SP.

* A quem a correspondência deve ser enviada. possibilita sua utilização no controle ou retardo do aparecimento de doenças crônicas, como doenças coronárias e diabetes melito [23].

No contexto atual da Ciência dos Alimentos e do consenso da relação alimentação-saúde-doença, existe grande solicitação por alimentos que além de fornecer os nutrientes indispensáveis ao organismo, proporcionem benefícios adicionais à saúde. A denominação nutracéuticos, comum na literatura, poderia induzir confusão nos consumidores, e por isso, no Brasil, a utilização do termo alimento ou ingrediente funcional é recomendada pela Vigilância Sanitária [6,7].

Dentro desta perspectiva, as atuais recomendações nutricionais, incentivam a expansão da ingestão de aveia e cevada mais ricas em $\beta$-glucanas, sendo necessária uma adequada caracterização tanto dos teores contidos nos grãos como dos efeitos fisiológicos implicados.

Dada a procura por análise de $\beta$-glucanas e devido à inexistência no Brasil de um laboratório que o realize, nos propusemos a testar o método recomendado pela AOAC [1] para análise de $\beta$-glucanas. A inclusão da composição básica neste estudo visa uma melhor caracterização dos cultivares em estudo, por ser esta a primeira característica que se aprecia de qualquer alimento, seja para consumo direto como para elaboração industrial de outros produtos alimentícios. E também, porque o processamento de alimentos, sempre provoca perda de parte dos nutrientes contidos nos alimentos in natura. 


\section{2 - MATERIAIS E MÉTODOS}

\section{1 - Material}

Foram utilizados grãos cultivados e selecionados pelo Instituto Agronômico de Campinas (IAC), aveia (Avena sativa), cevada (Hordeum vulgare), trigo (Triticum vulgare) e triticale (Triticum secale). As 14 amostras comerciais incluídas no estudo, foram obtidas em supermercados da cidade de São Paulo.

\begin{tabular}{|c|c|}
\hline NÚMERO & DESCRIÇÃO DA AMOSTRA \\
\hline 1 & aveia em flocos \\
\hline 2 & aveia em flocos \\
\hline 3 & aveia em flocos \\
\hline 4 & aveia em flocos \\
\hline 5 & farelo de aveia \\
\hline 6 & farinha de aveia \\
\hline 7 & $\begin{array}{l}\text { aveia integral, farelo de trigo, acúcar, } \\
\text { gérmen de trigo, gergelim, coco ralado, uva } \\
\text { passa, mel, sal, corante }\end{array}$ \\
\hline 8 & $\begin{array}{l}\text { flocos de milho, açúcar demerara, aveia } \\
\text { tostada, flocos de arroz, coco ralado, } \\
\text { gordura vegetal hidrogenada, sal }\end{array}$ \\
\hline 9 & $\begin{array}{l}\text { flocos de milho, aveia tostada, açúcar } \\
\text { demerara, aveia em flocos, uvas passas, } \\
\text { maçã desidratada, flocos de arroz, malte em } \\
\text { pó, mel, sal, farelo de trigo, coco ralado e } \\
\text { vitaminas }\end{array}$ \\
\hline 10 & $\begin{array}{l}\text { flocos de aveia integral, açúcar, óleo vegetal, } \\
\text { extrusado de trigo, farinha de arroz, coco } \\
\text { ralado, farinha de trigo, xarope de glucosa, } \\
\text { mel, sal, cacau desengordurado, glúten de } \\
\text { trigo, extrato de malte seco, aromatizante }\end{array}$ \\
\hline 11 & $\begin{array}{l}\text { trigo, cevada, açúcar, aveia, maltodextrina, } \\
\text { vitaminas e sais minerais }\end{array}$ \\
\hline 12 & $\begin{array}{l}\text { farelo de trigo, açúcar, extrato de malte, sais } \\
\text { minerais e vitaminas }\end{array}$ \\
\hline 13 & $\begin{array}{l}\text { farelo de trigo e aveia, farinha de trigo, } \\
\text { stevia, vitaminas e sais minerais }\end{array}$ \\
\hline 14 & $\begin{array}{l}\text { farelo de trigo, amido, farelo de milho, } \\
\text { vitaminas, sais minerais e corante }\end{array}$ \\
\hline
\end{tabular}

As amostras recebidas do IAC na forma de grãos inteiros, foram acondicionadas em frascos e armazenadas a $-18^{\circ} \mathrm{C}$. No momento da análise, foram estabilizadas térmicamente em dessecador e descascados manualmente. As amostras de cevada foram recebidas com e sem casca e foram utilizadas como recebidas, isto é, com e sem casca. As amostras de trigo e triticale foram todas recebidas sem casca. Os grãos foram triturados em moinho de facas e peneirados em tamis de $0,5 \mathrm{~mm}$ de abertura. As amostras comerciais foram submetidas ao mesmo tratamento.

\section{2 - Análises químicas}

A determinação de $\beta$-glucanas foi conduzida como descrito por Mc CLEARY e MURGFORD [16] que é o método oficial da AOAC, utilizando o kit da Megazyme International Ireland Ltd., Irlanda, que contém as enzimas que hidrolisam $\beta$-glucanas, liquenase (EC 3.2.1.73) e $\beta$-glucosidase (EC 3.2.1.21): 80 - 100mg da farinha foram aquecidos em água para hidratação e gelatinização das $\beta$-glucanas e a seguir submetidos à ação da liquenase. Posteriormente, após filtração e ajuste do $\mathrm{pH}$, a solução foi submetida à $\beta$-glucosidase para transformação dos oligossacarídeos em glicose, a qual foi determinada pelo método da glicose-oxidaseperoxidase. Uma parte da solução foi tratada diretamente com glicose-oxidase para determinação da glicose livre.

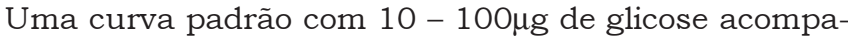
nhou todas as determinações. As amostras comerciais que continham açúcar, foram previamente tratadas com etano1 80\% [16]. Em todas as amostras foi realizada análise da composição centesimal, sendo: umidade, cinzas e lipides como recomendado pelo Instituto Adolfo Lutz [13]. Proteinas pelo método de micro-kjeldahl [1] com sulfato de cobre como catalisador da digestão. Fibra alimentar total (FAT) pelo método enzimico-gravimêtrico [1], substituindo a celite por lã de vidro (Merck) no processo de filtração, adaptação padronizada em nosso laboratório pela Dra. Tullia M. C. Filisetti (comunicação pessoal). Os carboidratos disponiveis foram obtidos por diferença. Todas as análises foram realizadas em triplicata, exceto a análise de fibra que foi duplicata.

\section{3 - RESULTADOS E DISCUSSÃO}

A composição dos grãos e dos produtos comerciais estão nas Tabelas 1 e 2 .

TABELA 1. Composição centesimal de aveia, trigo, triticale e cevada. *

\begin{tabular}{|c|c|c|c|c|c|c|}
\hline Amostra & Umidade & Cinzas & Proteínas & Lípides & $\mathrm{FAT}^{\star *}$ & $\begin{array}{c}\text { Carboidratos } \\
\text { disponíveis }\end{array}$ \\
\hline Aveia IAC-7 & 10,88 & 1,62 & 13,29 & 5,57 & 13,12 & 55,52 \\
\hline Aveia IAC-Preta & 11,15 & 2,06 & 14,55 & 4,97 & 15,02 & 52,25 \\
\hline Trigo IAC-24 & 12,43 & 1,47 & 11,44 & 1,92 & 13,94 & 58,72 \\
\hline Trigo IAC-289 & 12,53 & 1,52 & 10,60 & 1,91 & 14,89 & 58,54 \\
\hline Trigo IAC-350 & 12,02 & 1,48 & 13,99 & 1,91 & 14,56 & 56,04 \\
\hline Trigo IAC-364 & 12,27 & 1,60 & 14,67 & 2,15 & 15,03 & 54,28 \\
\hline Trigo IAC-370 & 12,67 & 1,53 & 13,31 & 1,56 & 14,92 & 56,01 \\
\hline Triticale IAC-2 & 11,86 & 1,77 & 11,68 & 2,34 & 13,81 & 58,54 \\
\hline Triticale IAC-3 & 11,89 & 1,81 & 6,45 & 1,80 & 12,90 & 65,15 \\
\hline Cevada IACCB8403-222 & 10,65 & 1,74 & 9,29 & 2,71 & 16,69 & 58,92 \\
\hline Cevada IACCB8403-245 & 11,13 & 1,85 & 10,12 & 2,40 & 17,94 & 56,56 \\
\hline Cevada IACCB8404-292 & 10,28 & 1,84 & 8,66 & 2,46 & 17,60 & 59,16 \\
\hline Cevada IACCB8404-296 & 11,50 & 1,73 & 9,43 & 1,84 & 15,20 & 60,30 \\
\hline Cevada IACCB8501-12 & 14,02 & 1,63 & 10,75 & 2,09 & 12,27 & 59,24 \\
\hline Cevada IACCB8501-22 & 13,19 & 1,42 & 9,94 & 1,98 & 12,25 & 61,22 \\
\hline Cevada IACCB8501-31 & 12,76 & 1,63 & 10,37 & 2,45 & 11,14 & 61,65 \\
\hline Cevada IACCB8501-63 & 12,48 & 1,55 & 10,27 & 2,25 & 12,52 & 60,93 \\
\hline Cevada IACCB75741 & 10,45 & 1,49 & 7,48 & 2,41 & 12,57 & 65,60 \\
\hline Cevada IBON139/83 & 13,05 & 1,48 & 9,48 & 2,02 & 10,72 & 63,25 \\
\hline
\end{tabular}


Os carboidratos totais correspondem à somatória dos carboidratos disponiveis e fibra alimentar total.

A composição básica da aveia (Aveia sativa) foi confrontada aos dados fornecidos no "site" do LATINFOOD [14]. Os cultivares analisados apresentaram valores muito similares com os da referida tabela.

Os valores dos demais grãos foram comparados com os da Tabela de Composição de Alimentos do Departamento de Agricultura dos Estados Unidos (USDA)[19]. Os 2 cultivares de triticale analisados, IAC- 2 e IAC-3, além da notável diferença nas proteínas $(11,68$ e 6,45\% respectivamente), eram menores que a tabela de referencia $(13,2 \%)$, valor que pode ser o conteúdo de proteínas de um cultivar geneticamente melhorado. O triticale é um híbrido de trigo e centeio que desde sua obtenção continuou sendo submetido a cruzamentos visando melhorar a cultura em diversos aspectos, entre eles seu conteúdo protéico. A composição dos cultivares de trigo, comparada com a mesma tabela [19], não mostrou discrepância relevantes e pelos teores de proteina encontrados, possivelmente correspondem a trigos duros (IAC-24, IAC-350, IAC-364 e IAC-370, com 11,44; 13,$99 ; 14,67$ e $13,31 \%$ respetivamente) e trigo mole (IAC289 , com 10,60\%) Quanto aos valores de proteinas dos cultivares de cevada (Hordeum vulgare), observamos uma ampla variação que se explica por serem cultivares obtidos dentro do Programa de Melhoramento Genético do IAC. O menor teor foi do cultivar IACCB75741 $(7,48 \%)$ e o maior do IACCB8501-12 (10,75\%), porém ambos abaixo da tabela americana para o grão integral. Os demais nutrientes não mostraram discrepância importante com os da referida tabela.

TABELA 2. Composição centesimal dos alimentos que contém cereais. *

\begin{tabular}{ccccccc}
\hline Amostra & Umidade & Cinzas & Proteinas & Lípides & FAT** & $\begin{array}{c}\text { Carboidratos } \\
\text { disponíveis }\end{array}$ \\
\hline 1 & 9,98 & 1,67 & 14,26 & 6,32 & 14,32 & 53,45 \\
2 & 9,83 & 1,64 & 14,06 & 6,40 & 14,41 & 53,66 \\
3 & 9,45 & 1,77 & 12,73 & 8,96 & 13,86 & 53,23 \\
4 & 8,13 & 1,76 & 14,88 & 8,95 & 16,93 & 49,35 \\
5 & 9,56 & 2,82 & 16,05 & 7,13 & 18,19 & 46,25 \\
6 & 8,92 & 1,52 & 12,32 & 10,03 & 11,20 & 56,01 \\
7 & 4,16 & 1,42 & 9,49 & 3,45 & 7,31 & 74,17 \\
8 & 4,25 & 1,63 & 6,03 & 7,48 & 11,25 & 69,36 \\
9 & 6,17 & 1,78 & 8,87 & 4,20 & 9,33 & 69,65 \\
10 & 5,85 & 1,55 & 6,98 & 17,20 & 7,62 & 70,79 \\
11 & 5,42 & 4,51 & 10,05 & 2,65 & 6,15 & 71,22 \\
12 & 6,89 & 4,77 & 11,92 & 2,05 & 27,55 & 46,82 \\
13 & 3,21 & 4,53 & 12,03 & 2,08 & 37,20 & 40,95 \\
14 & 3,83 & 4,55 & 7,27 & 2,38 & 38,29 & 43,68 \\
\hline 14 & & & & & & \\
\hline
\end{tabular}

*Base úmida
**FAT: fibra alimentar total

A composição centesimal dos produtos comerciais (Tabela 2) parece refletir a formulação declarada no ró- tulo, com os maiores teores de proteina nas amostras que contém somente aveia (1 a 6). Porém, omissão nos rótulos da proporção de cada ingrediente, não permitiu uma comparação mais acurada da composição dos grãos (Tabela 1) com a dos produtos comerciais.

Nas amostras de farelo de cereais (amostras 12, 13 e 14), os maiores teores de proteina foram das que tinham aveia (amostras 12 e 13). Por outro lado, os maiores valores para fibra alimentar correspondem a estas últimas três amostras. A amostra 5, que tem composição declarada de "farelo de aveia", apresentou um valor de fibra muito baixo e nós não encontramos uma explicação para isso.

Comparando entre nutrientes determinados (Tabela 2) com nutrientes declarados no rótulo, somente 4 amostras apresentaram um teor de proteinas menor que o declarado no rótulo (amostras 11, 12, 13 e 14 com valores 25, 20, 30 e $12 \%$ menores que os declarados). A legislação brasileira tolera 20\% para mais e para menos nos valores constantes na informação nutricional do rótulo.

Diferenças significativas entre valores determinados e declarados no rótulo dos produtos comerciais, se deram no caso da fibra. Os declarados eram menores que os determinados pelo método enzímico-gravimétrico. Somente em 3 amostras estes valores coincidiram (amostras 12, 13 e 14). Em duas delas os valores declarados eram 10 vezes menores que os determinados (amostras 1 e 2). Duas amostras declaravam valores de fibra entre 3 e 6 vezes menores que os determinados (amostras 7 e 8). Nas demais amostras os valores declarados eram entre 1 e 2 vezes menores que os determinados (amostras $3,4,5,6,9,10$ e 11). Provavelmente as diferenças se devem à metodologia utilizada na determinação de fibra, que não deve ser a mais adequada. Valores baixos de fibra superestimam o valor dos carboidratos disponiveis, quando calculados por diferença e, conseqüentemente, superestimam o valor calórico do produto. Além disso, para calcular as calorias, alguns dos produtos comerciais incluiam o teor de fibra, e sabemos que a fibra alimentar, cumpre um papel fisiológico mas, não tem valor calórico.

As Tabelas 3 e 4 apresentam os teores de $\beta$-glucanas nos grãos de cereais e nas amostras comerciais, respetivamente.

O método utilizado na determinação de $\beta$-glucanas é de fácil execução, a maioria das etapas analíticas são conduzidas num mesmo tubo de ensaio, diminuindo a possibilidade de erros. Na determinação da glicose liberada, em lugar de uma única concentração de glicose como fator de correção, utilizamos curva padrão de glicose, por considerá-la mais coerente no cálculo dos resultados. Outra vantagem do método enzimático é que não há necessidade de utilizar amostra desengordurada porque os lipides não interferem na determinação. $O$ método foi inicialmente testado com amostras certificadas de aveia e cevada recebidas da MEGAZYME.

Os grãos de aveia e cevada foram os que apresentaram maior teor de $\beta$-glucanas (Tabela 3). Os 2 cultivares de aveia apresentaram concentrações muito próximas 
entre si, 6,48 e 5,24\% para IAC-7 e IAC-preta, respetivamente. DE SÁ et al. [9] analisando cultivares brasileiros de aveia, encontraram 6,5\% para IAC-7 e 4,30: 3,78 e $3,51 \%$ para os cultivares UFRGS14, UPF17 e UPF16, respectivamente, mostrando que fatores genéticos determinam o teor de $\beta$-glucanas dos grãos, porém o ano da safra também interfere.

TABELA 3. Teor de $\beta$-glicanas em aveia, trigo e cevada. *

\begin{tabular}{lc}
\hline Amostra & $\beta$-glicanas (\%) \\
\hline Aveia IAC-7 & 6,48 \\
Aveia IAC-Preta & 5,94 \\
Trigo IAC-24 & 0,55 \\
Trigo IAC-288 & 0,54 \\
Trigo IAC-350 & 0,51 \\
Trigo IAC-364 & 0,66 \\
Trigo IAC-370 & 0,72 \\
Triticale IAC-2 & 0,47 \\
Triticale IAC-3 & 0,50 \\
Cevada IAC CB8403-222 & 7,00 \\
Cevada IAC CB8403-245 & 6,06 \\
Cevada IAC CB8404-292 & 5,42 \\
Cevada IAC CB8404-296 & 7,56 \\
Cevada IAC CB8501-12 & 9,68 \\
Cevada IAC CB8501-22 & 3,82 \\
Cevada IAC CB8501-31 & 7,03 \\
Cevada IAC CB8501-63 & 2,04 \\
Cevada IAC CB75741 & 4,05 \\
Cevada IBON139/83 & 3,18 \\
\hline &
\end{tabular}

* Base seca

GUTKOSKI e TROMBETTA [12] encontraram variação de 3,01 a 4,13 \% no conteúdo de $\beta$-glucanas de 7 variedades de aveia de interesse da Comissão Brasileira de Pesquisa de Aveia. DE SÁ et al. [10] mostraram que diversos tratamentos durante o processamento industrial da aveia não alteram os teores de $\beta$-glucanas.

Nas 10 variedades de cevada por nos analisadas, os teores de $\beta$-glucanas oscilaram de 2,04 a 9,68\% mostrando mais uma vez a variabilidade genética entre os cultivares. Estes resultados serão utilizados pelo IAC na classificação dos cultivares de cevada em relação ao conteúdo de $\beta$-glucanas. Existe atualmente grande interesse na obtenção de cultivares com elevados teores de $\beta$ glucanas. O Instituto Agronômico de Campinas possui um número significativo de cultivares de cevada (Hordeum vulgare), desenvolvidas dentro do Programa de Melhoramento Genético de Sementes e cujo conteúdo de $\beta$-glucanas não foi ainda determinado (comunicação pessoal). Trigo e triticale detinham teores de $\beta$-glucanas menores que $1 \%$. Nos 6 cultivares de trigo, a variação foi de 0,51 a $0,72 \%$. Nos dois cultivares de triticale, IAC-2 e IAC-3, as percentagens foram 0,47 e $0,50 \%$, respetivamente. Para as amostras de cevada, trigo e triticale, não foram incluídos valores de comparação de $\beta$-glucanas. Na literatura existem menos dados para estes grãos, muitos deles baseados em métodos analiticos menos específicos que o utilizado neste trabalho, ou ainda, utilizando métodos de extração de $\beta$-glucanas não são quantitativos [21].

TABELA 4. Teor de $\beta$-glucanas em alimentos que contém cereais. *

\begin{tabular}{ll}
\hline Amostra & Beta-glicanas (\%) \\
\hline 1 & 6,56 \\
2 & 6,10 \\
3 & 5,33 \\
4 & 7,56 \\
5 & 9,68 \\
6 & 3,82 \\
7 & 7,03 \\
8 & 2,04 \\
9 & 4,05 \\
10 & 3,18 \\
11 & 0,82 \\
12 & 1,46 \\
13 & 2,48 \\
14 & 0,82 \\
\hline
\end{tabular}

* Base seca

A Tabela 4 mostra o conteúdo de $\beta$-glucanas dos produtos comerciais. O maior teor, (amostra 5), corresponde ao farelo de aveia, seguido pela aveia em flocos (com exceção da amostra 7 que é uma fórmula com aveia). Seguem-se as formulações que contém aveia (amostras 9 e 10), sendo a amostra 11 uma exceção porque contém aveia e apresenta um teor muito baixo de $\beta$-glucanas. As amostras 12, 13 e 14 correspondem a fibra, porém somente a amostra 13 contém farelo de aveia explicando o teor mais elevado de $\beta$-glucanas $(2,48 \%)$.

Quanto ao método apresentado queremos sublinhar que é específico para determinação de $\beta$-glucanas de cereais com ligações glicosídicas $\beta(1 \rightarrow 3)$ e $\beta(1 \rightarrow 4)$. Este método não determina $\beta$-glucanas de Agaricus Blazei Merril (Cogumelo do Sol) que apresenta ligações glicosídicas $\beta(1 \rightarrow 3)$ e $\beta(1 \rightarrow 6)$. Esta afirmação foi confirmada pelo Dr McCleary (via e-mail). Na literatura é comum encontrar essa aplicação inadequada do método, resultando em valores de $\beta$-glucanas muito baixos.

Quanto aos efeitos fisiológicos das $\beta$-glucanas, enquanto as ligações $\beta(1 \rightarrow 3)$ parecem ser fundamentais para tais efeitos, as que possuem além disso ligações $\beta(1 \rightarrow 6)$ estimulam o sistema imunológico, enquanto as que apresentam ligações $\beta(1 \rightarrow 3)$ e $\beta(1 \rightarrow 4)$ diminuem o colesterol sangüineo e a glicemia [2]. Estes aspectos das $\beta$-glucanas precisam ser claramente estabelecidos, a atividade fisiológica melhor definida assim como o beneficio ou não de estimular o consumo. Caso esta necessidade seja comprovada, a utilização de $\beta$-glucanas como 
hidrocoloides em alimentos seria uma forma de aumentar seu consumo, a elevada viscosidade de suas soluções aquosas, junto com a maior palatabilidade, comparado a outros hidrocolóides de uso habitual em alimentos os habilita plenamente para isto [3].

\section{4 - CONCLUSÕES}

O método enzimático é apropriado para a determinação de $\beta$-glucanas em cereais, É específico para determinação de $\beta$-glucanas com ligações glicosídicas do tipo $\beta(1 \rightarrow 3)$ e $\beta(1 \rightarrow 4)$. Aveia (Aveia sativa) e cevada (Hordeum vulgare) são os cereais com maiores teores de $\beta$-glicanas. O conteúdo de $\beta$-glicanas dos produtos comerciais mantém relação com o tipo de cereal que contém na fórmula, sendo o constituído de farelo de aveia puro o que apresentou maior teor de $\beta$-glicanas.

\section{5 - REFERÊNCIAS}

[1] ASSOCIATION OF OFFICIAL ANALYTICAL CHEMIST. Official Methods of Analysis of the AOAC. 15ed. Washington, Assoc. Off. Agric. Chem., 1990.

[2] BOHN,J.A; BEMILLER,J.N., ( $1 \rightarrow 3)-\beta$-D-glucans as a biological response modifiers: a review of structure-functional activity relationships. Carbohydrate Polymers, v.28, p.3-14, 1995.

[3] BRAATEN, J.T.; WOOD, P.J.; SCOTT,F.W.; RIEDEL, K.D., Oat gum lowers glucose and insulin after an oral glucose load. American Journal of Clinical Nutrition, v.53, p.1425- 1430,1991.

[4] BRAATEN, J., WOOD, P. J., SCOTT, F. W., WOLYNETZ, M. S., LOWE, M. K., BRADLEY-WHITE, P., AND COLLINS, M. W. Oat $\beta$-glucan reduces blood cholesterol concentration in hypercholesterolemic subjects. European Journal of Clinical Nutrition v. 48, p.465474, 1994.

[5] BOURDON, I.; YOKOYAMA, W.; DAVIA, P.; HUDSON, C.; BACKUS, R.; RICHTER, D.; KNUCKLES, B.; SCHNEEMAN, B. Postprandial lipid, glucose, insulin, and cholecystokinin responses in men fed barley pasta enriched with $\beta$-glucan. American Journal of Clinical Nutrition, v. 69, p. 55-63, 1999

[6] CÂNDIDO, L.M.B.; CAMPOS, A.M. Alimentos funcionais Uma revisão. Boletim da SBCTA, v.29, n.2, p.1993-203, 1995

[7] COLLI,C. Nutracêutico é uma nova concepção de alimento. Informativo da Sociedade Brasileira de Alimentação e Nutrição, ano VII, n.1, p.1-2, 1998.

[8] CZOP, J.K.; AUSTEN, K.F., A $\beta$-glucan inhibitable receptor on human monocytes: its identity with the phagocyte receptor for particulate activators of the alternative complement pathway. Journal of Immunology, v. 134, p. 2588-2593, 1985.

[9] DE SÁ, R.M.; DE FRANCISCO, A.; OGLIARI,P.J.; BERTOLD,F.C. - Variação no conteúdo de Beta-glucanas em cultivares Brasileiros de aveia. Ciênc.Tecnol.Alim., v. 20, n. 1, p. 99-102, jan/fev 2000.

[10] DE SÁ, R.M.; DE FRANCISCO, A.;SOARES, F.C.T. - Concentração de $\beta$-glucanas nas diferentes etapas do pro- cessamento da aveia (Aveia sativa L.) Ciênc.Tecnol. Alim., 18(4):425-427, out/dez, 1998

[11] FLEMING,M.; KAWAKAMI,K. Studies of the fine structure of $\beta$-D-glucans of barleys extracted at different temperature, Carbohydrate Research, v. 57, p. 15-23, 1977.

[12] GUTKOSKI, L.C.; TROMBETTA,C. - Avaliação dos teores de fibra alimentar e de Beta-glicanas em cultivares de aveia (Avena sativa L) Ciênc. Tecnol. Alim., v. 19, n. 3, p. 387-390, set/dez 1999.

[13] INSTITUTO ADOLFO LUTZ. Normas analíticas do Instituto Adolfo Lutz, Métodos químicos e físicos para análise de alimentos, v. 1, $3^{\text {a }}$ ed., São Paulo, Instituto Adolfo Lutz, 1985.

[14] LATINFOODS - www.rlc.fao.org/bases/

[15] LIA, A.; ANDERSON, H.; MEKKI, N.; JUHEL, C.; SENFT, M.; LAIRON, D., Postprandial lipemia in relation to sterol and fat excretion in ileostomy subjects given oat-bran and wheat test meals. American Journal of Clinical Nutrition v. 66, p. 357-365, 1997.

[16] McClEARY, B.V.; MUGFORD, D.C. - Determination of $\beta$ glucan in barley and oats by streamlined enzymatic method: summary of collaborative study. Journal of AOAC International, v. 80, n.3, p. 580-583, 1997.

[17] McINTOSH, G.H.; WHYTE, J.; McARTHUR, R.; NESTEL, P.J. - Barley and wheat foods: influence on plasma cholesterol concentrations in hypercholesterolemic men. American Journal of Clinical Nutrition, v. 53, p. 12051209, 1991.

[18] POUlTER, N.; CHANG, C. L.; CUFF, A.; POUlTER, C.; SEVER, P.; THOM, S. Lipid profiles after the daily consumption of an oat-based cereal: A controlled crossover trial. American Journal of Clinical Nutrition v.58, p.66, 1993.

[19] USDA - www.nal.usda.gov/fnic/foodcomp/

[20] WAHNEFRIED, W.D.; BOWERING, J.; COHEN, P.S., Reduced serum cholesterol with dietary change using fat-modified and oat bran supplemented diets. Journal American Dietetical Association v. 90, p. 223-229, 1990.

[21] WOOD,P.J.; SIDDIQUI,J.R.; PATON,D., Extraction of high viscosity gum from oats, Cereal Chemistry, v.55, n.6, p. 1038-1049, 1978.

[22] WOOD,P.J.; WEISZ,J.; BLACKWELL,B.A, Molecular characterization of cereal $\beta-D$-glucans. Structural analysis of oat $\beta-\mathrm{D}$-glucans and rapid structural evaluation of $\beta-D$-glucans from different sources by highperformance liquid chromatography of oligosaccharides released by lichenase, Cereal Chemistry v.68, p.31-39, 1991.

[23] YOKOYAMA, W.H.; HUDSON, C.A.; KNUCKLES, B.E.; CHIU, M.M.; SAYRE, R.N.; SAYRE, J.R.; SCHNEEMAN, B.O., Effect of barley $\beta$-glucan in durum wheat pasta on human glycemic response. Cereal Chemistry, v. 74, n. 3, p.293-296, 1997.

\section{6 - AGRADECIMENTOS}

Este trabalho foi realizado com suporte financeiro da Fundação de Amparo à Pesquisa do Estado de São Paulo (FAPESP). 